\title{
Course Practice Teaching Mode Based on the Exploration of Online and Offline Integration
}

\author{
Mingwei Bian \\ Chengdu Radio and TV University, China \\ bianmingwei@163.com
}

Keywords: course practice teaching mode; online; offline; integration; exploration

\begin{abstract}
In this paper, Open University of China (Chengdu Branch) Open Education Business Administration (college) students of "Marketing" course as a research vehicle to farm and experience the teaching activities of the main store as discussed based on online and offline phasor fusion practical teaching strategies, put forward the theory and practice, classroom and on-site, online and offline integration courses and practice teaching mode, entertaining, instruction in life, fully activate the enthusiasm of student learning process, participation, initiative, interest, responsibility and sense of cooperation.
\end{abstract}

\section{Introduction}

Training objectives National Open University Open Education Business Administration (college) students, that is the basic theory of culture in business administration and marketing, the application of basic skills, the basic method, with enterprise-level managers and market operators of basic literacy and capacity talents. In order to effectively achieve the above training objectives, Open University of China (Chengdu Branch) on the professional core curriculum put forward the theory and practice, classroom and on-site, online and offline integration courses and practice teaching mode, aimed at forging a comprehensive student the practical operation ability and practical training applied talents for the development of local economy and society.

Based on the integration of online and offline courses and practice teaching mode Background

Online and offline integration and Background Practice Teaching Model of Open Education is that the professional practice and integrated practice curriculum teaching status quo is not satisfactory, basically in a "mere formality" or "neglected" state, each open education professional status of teaching practice as set forth below.

Focus on imparting knowledge, ignored Ability

Currently, the Open University of China most courses taught mainly in theory-based, ignoring the cultivation of students' practical abilities. Course more emphasis on curriculum theory to explain the contents of the course practice mainly in the form of coursework to complete, life lessons practice even less. Students practice concentrated mainly rely on practice teaching to carry out, and concentrate basically teaching sexual practices are on the third or fourth semester, students are required to learn and then be completely portion theoretical knowledge, theory and practice the time interval longer period, it is difficult to achieve the desired practical ability to enhance the effect.

The practical aspects of centralization, limited teaching effect

Currently, the Open University of China most cultural and economic class professional focus is the completion of the practical teaching social studies and thesis, science and engineering 
professional focus of practice teaching is completed practical training reports and graduation design, whether it is social investigation report or practical training reports is required by means of practical teaching bases or simulation training lab to complete. From now, the majority of school units, and not established practice teaching base in the true sense, experimental training equipment and conditions are also wide disparities exist, a large concentration of teaching practice and has not been effectively carried out, concentration the effect of practical teaching is not optimistic.

\section{Off-campus practice base, poor operating results}

Currently, the Open University of China all students off-campus practice teaching base are mostly companies, enterprises or other organizations operating in the market economy today, companies, enterprises or other business organization is an independent self-financing economic entities, no obligation or unwilling to provide students with internship service. The reason is that students practice short time, for the company's continuing existence of certain barriers to business development; economic profit organization does not intent to let students know their business secrets or exposure to non-standard business practices; In accordance with the principle of "old and new", internships students will occupy a lot of the old company employee working hours, pay close attention to economic benefits for the company's leadership, the general reluctance to accept student interns. Thus, the operating results campus practice teaching base is not ideal.

\section{The teachers teaching, lack of experience level}

Currently, the professional practice teaching Open University of China in general by the guidance of teachers in graduate school or university as professional teachers, most professional teachers are from the "college to TV," they never engaged in real business practice to work on concrete enterprise business environment is not experienced, practical teaching guide for students only on their own perception of textbook knowledge and ability to guide and explain its lack of authenticity and authority. At the same time, the majority of professional teachers are "behind closed doors", contact the school practitioners, communication little, good and bad teachers practice teaching to enhance students' practice has seriously affected the ability.

\section{Passive learning more active learning less}

Initiative is the primary feature of autonomous learning, active and passive student's specific learning activities are expressed as "I want to learn" and "want me to learn." Currently, the National Open University of the professional practice teaching curriculum, teachers teach students knowledge on the basis of professional rules, students active learners rarely, basically passive acceptance of teachers to impart knowledge. Most students still stuck in the "me 'stage, a small percentage of the students," I want to learn ", students active learning enthusiasm did not fully mobilized, so learning outcomes of learners by a certain extent.

\section{Based on the integration of online and offline courses and practice teaching mode of practical operation}

\section{Practice Teaching Design Life}

We believe that the course content comes from real life, but also for real life service. Practical certain course of production or life, reveals the relationship between teaching content and actual production or life. Contact with a particular emphasis on the specific course of life, how to focus on instructional design students learning from life experience and existing knowledge and understanding of the course, students explore consciousness, so that students learn to use the preliminary expertise and methods learned to solve some simple the practical problems. Open University of China (Chengdu Branch) "marketing" course in instructional design, organization and 
implementation, teaching strategies useful exploration, achieved a certain course of education quality.

\section{Diversification of Practical Teaching Mode}

We believe that through the network can break our limitations of classroom space, so that the classroom extends to the broader community, to achieve communication and integration of curricular and extracurricular. Course Tutorial combination of theory and practice of teachers seeking entry point, combined with educational institutions, the actual situation of the students attempt from life, appropriate life, "theoretical classroom teaching - Field Practice Teaching - online exchange Deepening - Analysis of classroom communication," the online and offline, and live interactive classroom teaching mode.

The class moved into the farm building "Experience + Dialogue + Network + Planning" mode

We rely on the schools helping object, "The most tide microblogging marketing farmers Lixue You" organic farms, the practice of the" Bus theoretical teaching + Teaching farm experience + Dialogue Teaching +Network depth interaction + Planning report sharing "Practical Teaching strategy.

Immediate south of college students are mostly part-time students, have some work experience and life experience, Combined with one of my school help object "Lixue You" healthy organic vegetables microblogging marketing as a teaching of the living body, to farming as a starting point, lead students to practice on-site experience, feeling the farm cultivation process, summarize highlights areas for improvement and marketing, in improving students' research skills, analytical skills, decision-making ability, for the farm business brainstorming.

Link one: bus theoretical teaching

Tutors use take the bus went to the farm on the way time, participation in the teaching activities of 40 students carriage theoretical teaching, focus on explaining the marketing of the eyeball economy, exchange, advertising, personal selling, sales promotion, public relations, microblogging marketing, micro-channel marketing; Lixue You introduced organic vegetable sales price, sales model and planting elements (land area, soil, air, water, fertilizer, planting process, etc.). For students to actively participate in the follow-up dialogue teaching theoretical foundation.

Link two: farm experience teaching

Teachers and students arrived farms by farmers as a practical teaching Lixue You tutors, farmers Lixue You lead us to recognize the vegetables, pick vegetables, sweet potato digging, planting organic healthy vegetables explain the whole process of farming and environmental protection philosophy, soil cultivation, seed selection, fertilization catch the worm, field management, harvesting vegetables, were the focus of talks, teachers and students to feel healthy organic vegetable cultivation process and culture, environmental protection farming experience.

Link three: dialogue teaching

Farmer Li Xueyou teachers and 40 students ( 8 teams, 5 people / group) discussion and in-depth exchanges, detailing its microblogging marketing legend, and the question raised by the various team members one by one to answer. For example: organic vegetables connotation, pricing model, sales model, sales channels, logistics and information communication tools and so on.

Link four: depth interactive network

40 students grouped in the field and online to explore Lixue You "Healthy vegetables + Microblogging marketing" success points less points and their improvements. Site experience and 
dialogue, students participate in online discussions with unprecedented enthusiasm, students actively speak, mutual inspiration, wisdom sparks frequently burst, within one hour, the teachers and students to interact posts reached 400, a lot of posts have larger practicality and value.

Link five: planning report share

Within a month's time, 40 students in the study group as a unit for the "Li Xueyou" plan "healthy vegetables + network marketing" creative marketing programs, and to study groups for the report creative solutions unit, invite Lixue You, marketing experts or actual teacher reviews Program.

\section{Link six: value-added activities}

To complete the dramatic experience of the process of, fun, entertaining, educational units also placed some game elements, such as when a farm field experience as a team to identify the vegetables Dishes activities to individual units to participate in the selection of about 1,000 words experience writing activities and can best embody the essence of the event photography activities, selected the outstanding works will show and give some incentives on the school website. In addition, students can personally pick vegetables from the farm, the rationale for him, personally cooking, and "school - breaks - do" integration.

The class moved into the supermarket, build a "Classroom + Store + Network + Classroom" model

We rely on "Sichuan University campus Education supermarket", the practice of the "Theoretical classroom teaching + Teaching Marketplace Experience +Network depth interaction +Group share Classroom" course practical teaching strategies.

Sichuan University study points directly under the age of students is relatively small, no practitioners work experience but there are certain life experiences, teachers select a medium-sized supermarket nearby (Sichuan University campus Education supermarket) as a teaching of the living body to store layout, store and create an atmosphere merchandise display as a starting point to lead the students into groups to enter the store observations, summarized highlights and areas for improvement store operations, to provide reference of theory and practice for students future employment and entrepreneurship.

Link one: theoretical classroom teaching

Tutors in the classroom teaching focus on the basic principles of marketing, consumer shopping psychology, found that demand, to meet demand, the theoretical knowledge of market research, marketing mix and so on.

\section{Link two: store experience teaching}

Tutors lead students in-depth store site teaching, teachers lead students to visit the store, and guide students display merchandise from the store site, Duitou display, light background, music scene, promotional etiquette, promotional techniques, warehouse management and other stores of cultural elements summarizes store marketing successes, shortcomings and suggest improvements.

Link three: network depth interaction

Tutors guide students to learn the team as a unit, arbitrarily selected stores in a commodity, combined with the marketing principle of classroom teaching to write creative marketing planning copy of the product, a statement in the course forum for discussion and exchange. Study group practice based on observations and written reports and after online communication on creative marketing planning copy optimization. 
Link four: Panel classroom to share

Tutors organize various groups reporting Marketplace Experience report in the classroom teaching practice, teachers review and given in recognition of outstanding programs and sent to store managers, to reach the perfect combination of theory and practice.

\section{The effect of the process of practice teaching}

We believe that when students are familiar with the learning content and background of life closer degree students to consciously accept the higher knowledge. Life is an inexhaustible source of Teaching, current textbooks and there are a lot of practical problems of student life experiences and real life. Teaching teachers not only to provide real-life material, the creation of student life close to the actual situation, recognize the reality of life from the perspective of observation programs, focusing on curriculum knowledge and actual contact, let the students observe the operation, speculation, exchange, reflection, etc. activities gradually realize the production of knowledge, the formation and development of a positive emotional experience, to feel the power of knowledge to enable students to learn look a gift horse, learned to use, so that students learn the course content from the source of mining life, depicting the practice of the teaching process to enhance students' organizational skills, communication skills, leadership, innovation, learning ability, calling capability and adaptability, fully in line with the Chengdu forging economic, high-quality application-oriented social development required, complex talent.

\subsection{Practice Teaching Evaluation multidimensional}

We believe that the practice teaching evaluation should be a $360^{\circ}$ assessment, evaluation subject should implement multidimensional, including student assessment teams, the school evaluation, evaluation of outside experts, industry enterprise evaluation, etc.

Students mainly evaluates the teaching practice guidance teachers' teaching attitude, teaching contents, teaching methods and teaching effects, etc.

Teaching evaluation teams to focus on the campus practice teaching counseling teachers' teaching efficiency and teaching quality, teaching attitude and teaching, etc.

Outside experts focus on evaluating the course design of practice teaching counseling teachers, curriculum design, curriculum design, content, teaching mode and teaching methods, etc.

Industry enterprise key evaluation practice teaching counseling teachers curriculum idea and train of thought, pertinence and applicability, course organization and arrangement, teaching mode, the application of information technology and course teaching ethics, ability and level, etc.

In summary, based on the implementation of the theory and practice of classroom and on-site, online and offline integration courses and practice teaching mode, designed to effectively alleviate the concentration of Practice Teaching shortcomings, the students theoretical knowledge and practical ability to merge culture, improve students 'knowledge structure, improve students' practical ability to train for local economic and social development required for application-oriented and practical talents were actively explored, is "everyone is learning, always able to learn, everywhere can learn" the country's open practice teaching philosophy deepened.

\section{Reference}

[1] Wang Dongfeng, strengthen students' vocational skills to promote employment of effective measures, Chinese Vocational and Technical Education, 2005(15):50-51.

[2] Li Jilin, situational teaching experiments and research, Sichuan Education Press, Chengdu, 2010 